\title{
Assessment of Rear-Surface Processing Strategies for III-V on Si Multijunction Solar Cells Based on Numerical Simulations
}

\author{
Diego Martín-Martín, Elisa García-Tabarés, and Ignacio Rey-Stolle
}

\begin{abstract}
The manufacturing of high-efficiency III-V on Si multijunction solar cells needs the development of hybrid, i.e., adapted to both families of materials, solar cell processing techniques, able to extract the full photovoltaic potential of both the subcells. This fact especially impacts the processing of the silicon rear surface of the tandem, which cannot receive treatments commonly used in the single-junction $\mathrm{Si}$ solar cell industry [Al-back surface field (BSF), thermal $\mathrm{SiO}_{2}$, and so on], since these would result in an excessive thermal load that would deteriorate the III-V upper layers (top cell, tunnel junction, and buffer layer). However, the $\mathrm{Si}$ bottom cell requires an advanced design with good rear passivation, a good ohmic contact, and good carrier selectivity, so that its contribution to the efficiency of the tandem is maximized. Accordingly, in this paper, several lowtemperature compatible rear-surface passivation techniques for the Si bottom subcell in a monolithic III-V/Si tandem solar cell are explored. In particular, aluminum BSFs, passivated emitter and rear cell (PERC)-like architecture, passivated emitter and rear locally diffused (PERL)-like architecture formed with low thermal loads, and heterojunction with intrinsic thin layer (HIT)like processes are assessed using numerical simulations, and a comparison of the Si bottom cell performance for the mentioned alternatives in a GaAsP/Si dual-junction solar cell is presented.
\end{abstract}

Index Terms-III-V on Si, multijunction solar cell, rear-surface passivation, $\mathrm{Si}$ processing.

\section{INTRODUCTION}

$\mathbf{T}$ HE INTEGRATION of III-V semiconductors on Si substrates has received a lot of attention over the last years. As a result of this impulse, good quality metamorphic III-V materials and the first complete tandem devices have been reported, demonstrating great promise toward the achievement of highly efficient III-V/Si solar cells [1], [2].
The vast majority of the efforts in this direction have been focused on the optimization of the heteroepitaxial growth of the III-V compounds on Si [1]-[4], with the primary goal of the minimization of crystal defects. Nonetheless, little to no work has focused on optimizing the device configuration and its processing [following the conventional III-V jargon, by processing we mean the technological steps that take place after epitaxy to complete the manufacturing of the solar cell, namely, surface passivation, contact formation, and antireflection coating (ARC) deposition]. Typically, the few implementations of III-V/Si devices reported so far have used the processing strategies of III-V solar cells for both the front and back contacts [i.e., evaporated front grid and full rear-side metallization, as shown in Fig. 1 (left)] [1], [2]. While for the top side of the structure (i.e., the front side of the III-V top subcell), this provides a standard and excellent solution it is not so for the rear side (back surface of the Si bottom subcell). A full metal coverage of the rear side [Fig. 1 (left)] leads to intolerably high recombination losses. Accordingly, several works have highlighted the importance of rear-surface passivation in the Si bottom cell in $\mathrm{GaAs} / \mathrm{Si}$ [5] or $\mathrm{GaAsP} / \mathrm{Si}$ dual-junction solar cells (DJSCs) [6]. Therefore, in order to fully exploit the efficiency potential of the tandem III-V/Si solar cell, the Si bottom subcell needs a more advanced processing-closer to what is done in conventional singlejunction silicon photovoltaic (PV) technology-that provides good rear passivation in addition to a good ohmic contact and good carrier selectivity [6]. In order to determine the best technological solution for this problem, in this paper, we review the restrictions of III-V/Si structures regarding rearside passivation (as compared with the conventional singlejunction Si solar cell technology) and analyze using numerical simulations the performance of a $\mathrm{Si}$ subcell in $\mathrm{GaAsP} / \mathrm{Si}$ metamorphic structure with an ideal back surface field (BSF) and several adapted rear processing alternatives, namely, aluminum BSFs, passivated emitter and rear cell (PERC)like architecture, passivated emitter and rear locally diffused (PERL)-like architecture formed with low thermal loads, and heterojunction with intrinsic thin layer (HIT)-like backside processing, to produce highly efficient bottom subcells for III-V/Si tandems.

\section{Potential of an Ideal Back Surface Field}

One of the most direct approaches for the rear-side processing in p-type $\mathrm{Si}$ solar cells is the incorporation of a $\mathrm{p}^{+}$ 


\section{Basic structure}

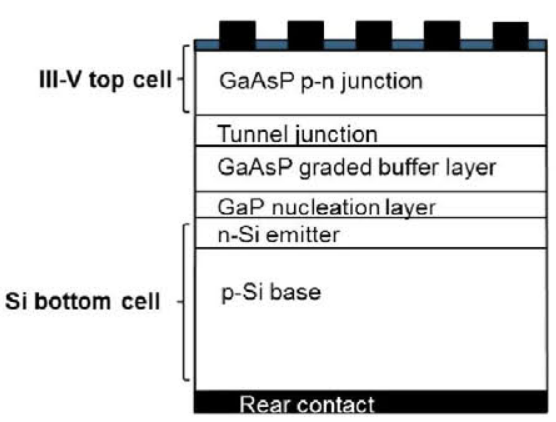

a) BSF

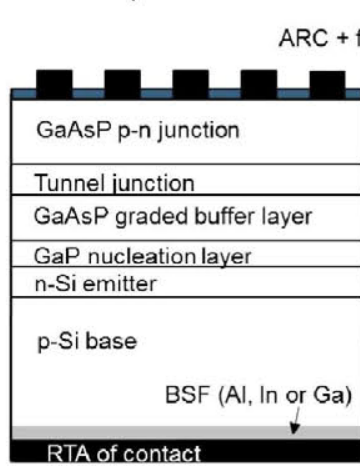

b) PERC-like Front grid c) HIT-like
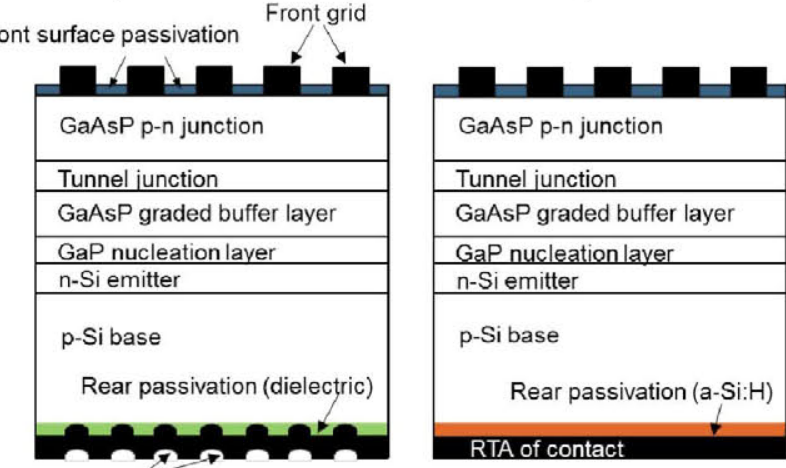

Local firing of Al contacts

RTA of contact

Fig. 1. Schematic of the suggested GaAsP/Si DJSC structures. Left: basic structure. Right: reviewed alternatives. (a) BSF structure. (b) PERC-like structure, with local rear contacts. (c) HIT-like passivating scheme.
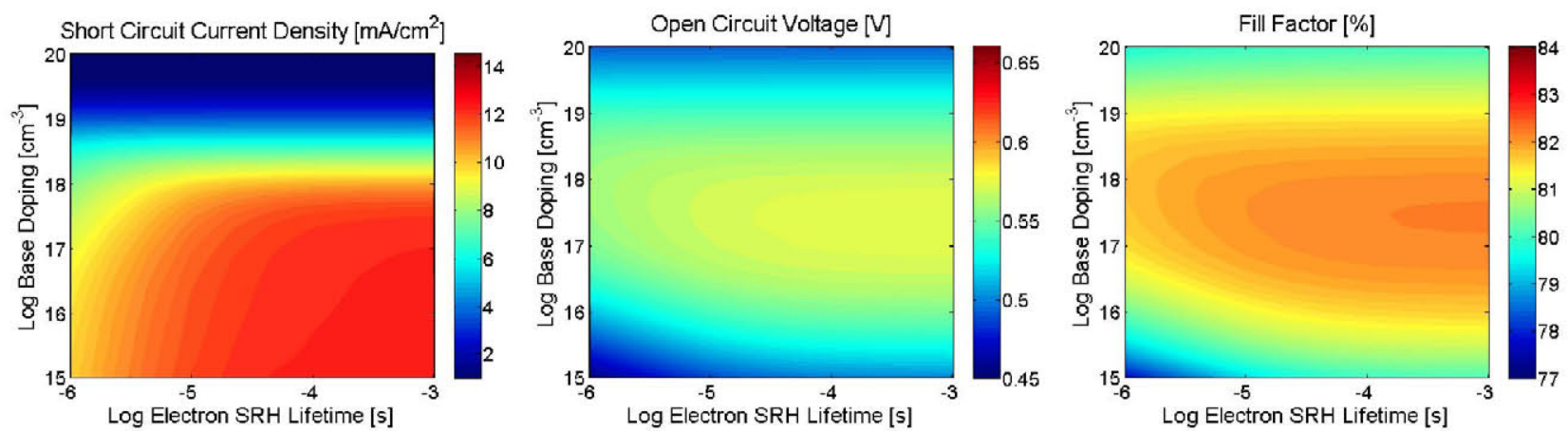

Fig. 2. Performance of the $\mathrm{n} / \mathrm{p} \mathrm{Si}$ bottom cell basic structure, in a GaAsP/Si DISC structure under 1-sun AM1.5G, as a function of base doping and minority carrier (electron) lifetime and with a GaP/Si IRV of $10^{6} \mathrm{~cm} / \mathrm{s}$ (without ARC). Left: $J_{\mathrm{SC}}$. Center: $V_{\mathrm{OC}}$. Right: FF.
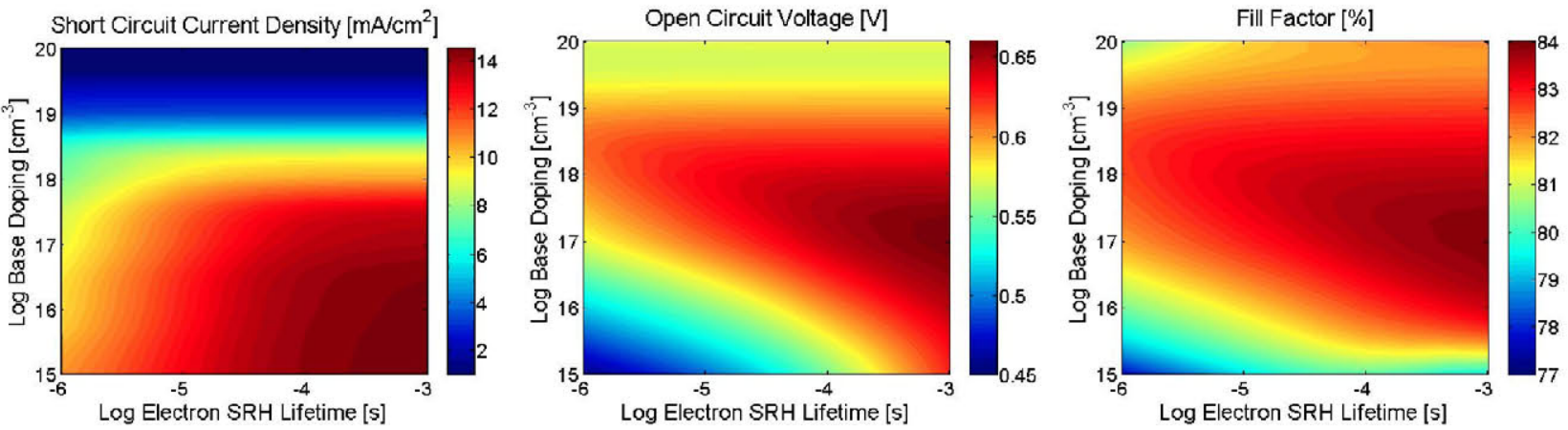

Fig. 3. Performance of a $\mathrm{n} / \mathrm{p}$ Si bottom cell with an ideal BSF, in a GaAsP/Si DJSC structure under 1-sun AM1.5G, as a function of base doping and minority carrier (electron) lifetime and a GaP/Si IRV of $10^{4} \mathrm{~cm} / \mathrm{s}$ (without ARC). Left: $J_{\mathrm{SC}}$. Center: $V_{\mathrm{OC}}$. Right: FF.

layer to create a BSF [7]. The $\mathrm{p}^{+}$-doped region improves the quality of the semiconductor-metal contact and keeps the minority carriers away from the highly recombining rear interface. To quantify its influence when $\mathrm{Si}$ forms the bottom active subcell in a GaAsP/Si DJSC, $J_{\mathrm{SC}}, V_{\mathrm{OC}}$, and Fill Factor (FF) under 1-sun AM1.5G illumination have been calculated for a $\mathrm{n} / \mathrm{p} \mathrm{Si}$ bottom cell, with no rear passivation [basic structure in Fig. 1 (left)] and with an ideal $1-\mu \mathrm{m}$ thick, $10^{20} \mathrm{~cm}^{-3}$ uniformly doped BSF [Fig. 1(a)], as a function of the Si bulk (electron) Shockley-Read-Hall (SRH) lifetime and substrate doping. The results are shown in Figs. 2 and 3, respectively. Figs. 2 and 3 show how the presence of the BSF not only yields the expected improvement of the 1-sun performance (maximum $J_{\mathrm{SC}}$ goes from 12.6 to $14.4 \mathrm{~mA} / \mathrm{cm}^{2}$ and maximum $V_{\mathrm{OC}}$ from 570 to $660 \mathrm{mV}$ ) but also makes that both $J_{\mathrm{SC}}$ and $V_{\mathrm{OC}}$ cease being limited by surface recombination, to become dominated by bulk phenomena. Consequently, any increase in the minority carrier lifetime in the Si subcell would produce a corresponding increase in its PV performance.

However, creating ideal BSF layers in III-V/Si structures is far from being easy. In particular, the key limitation of the 
process stems from the fact that it is not possible to treat the samples at high temperatures for long times once the epitaxial growth of the III-V materials has taken place. If this was done, III-V buffer layers and tunnel junctions would be noticeably degraded as a result of the high-thermal load. This fact hampers the use of conventional well-established processes of the Si PV industry once the III-V layers have been epitaxially grown on the substrate. Therefore, the development of a hybrid postprocessing technology to preserve the high-quality III-V/Si structure that is compatible with both the materials (i.e., $\mathrm{Si}$ and III-V semiconductors) needs to be addressed.

\section{Alternatives for Low-Temperature Rear-Side PROCESSING OF THE Si BOTTOM SUbCELL}

This section reviews the suitability of three strategies (schematically depicted in Fig. 1) for III-V/Si solar cell processing to obtain a high-quality passivation of the rear $\mathrm{Si}$ surface without exposing the III-V part to highthermal loads, which also would help maintain high bulk carrier lifetimes in the $\mathrm{Si}$ subcell through the processing. The performance for each strategy is analyzed and compared using the numerical simulations done with Silvaco ATLAS [8]. The simulated $\mathrm{Si}$ subcell structure includes the upper layers in a complete $\mathrm{GaAsP} / \mathrm{Si}$ metamorphic DJSC. It consists of a 90-nm, $2 \times 10^{18} \mathrm{~cm}^{-3}$ n-type epitaxial Si emitter on a $300-\mu \mathrm{m} 2 \times 10^{15} \mathrm{~cm}^{-3}$ p-Si base. Regarding the III-V part, it includes a $250-\mathrm{nm}$ n-GaP nucleation layer followed by a ten-step compositionally graded $2.5 \mu \mathrm{m}$ thick $\mathrm{n}$-GaAsP buffer $(0.07 \leq y \leq 0.70)$. The buffer is caped with a thick $2-\mu \mathrm{m} \mathrm{n}-\mathrm{GaAs}_{0.7} \mathrm{P}_{0.3}$ layer $\left(E_{G}=1.78 \mathrm{eV}\right)$, which simulates the absorption of the top cell. A moderate concentration of crystallographic defects is assumed at the $\mathrm{GaP} / \mathrm{Si}$ interface, and thus its interface recombination velocity taken in all simulations is $10^{4} \mathrm{~cm} / \mathrm{s}$. No surface charge is considered at the $\mathrm{GaP} / \mathrm{Si}$ interface. All the simulations have been done without ARCs. More details of the simulated structure can be found in [6].

In the quest for these strategies, we have only focused on the alternatives that would be performed after the epitaxial growth. It could be argued that some other alternatives for rear passivation could be implemented before the epitaxial step. In this way, the growth of the III-V layers would neither be degraded nor influenced by the subsequent high-thermal loads. Being this true, we believe that the epitaxial growth is probably the process with a higher impact on the production yield, and thus should be performed first (i.e., only wafers with a highquality epitaxy should undergo subsequent processing).

\section{A. Low-Temperature BSF}

Today, full-area aluminum screen printed and alloyed rear contact is the most common approach for manufacturing the industrial p-type $\mathrm{Si}$ conventional solar cells, due to its simplicity and low manufacturing costs [9]. Al is typically fired in belt furnaces at $\sim 750{ }^{\circ} \mathrm{C}-900{ }^{\circ} \mathrm{C}$, leading to $\mathrm{Al}$ peak concentrations in the range of $10^{18}-10^{19} \mathrm{~cm}^{-3}$ [10].

As discussed in the Section II, due to the high-thermal load required, such conventional Al-BSF is not compatible

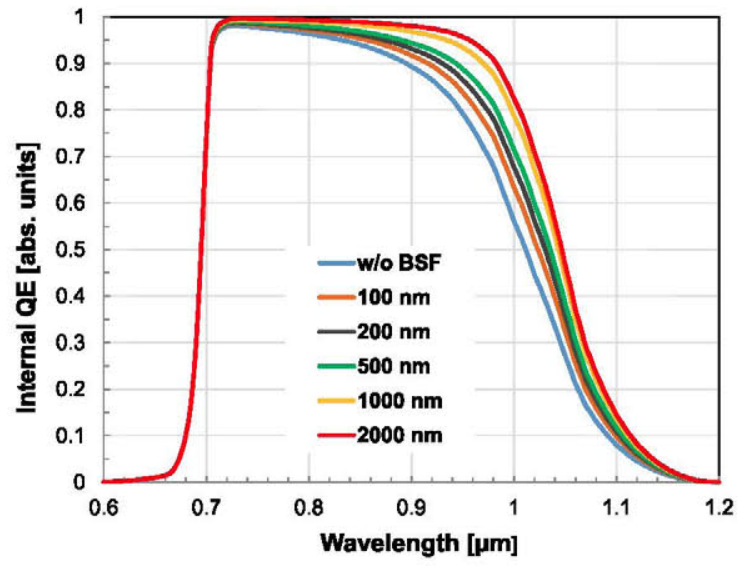

Fig. 4. IQE comparison for the Si bottom cell with ERFC-type LT-BSF as a function of the BSF depth $\left(N_{\text {peak }}=10^{19} \mathrm{~cm}^{-3}\right)$.

with the III-V/Si structures. Any attempt to form a BSF must keep the thermal budget as low as possible. The alternative would be the use of very fast firing processes at mediumto-low temperatures $\left(<700 \quad{ }^{\circ} \mathrm{C}\right)$ based on rapid thermal annealing (RTA). Candidate materials for this low-temperature BSF (LT-BSF) include not only Al but also Ga and In. In all the cases, shallow- and medium-doped rear diffusion profiles are expected. Rear-side processing would be completed by forming the back contact using $\mathrm{Al}$ evaporation or sputtering, followed by a second low-temperature annealing or RTA. A schematic representation of such a structure is depicted in Fig. 1(a).

Fig. 4 shows the simulated internal quantum efficiency (IQE) for the Si bottom subcell, assuming LT-BSF complementary error function (ERFC)-type shallow doping profiles, with a fixed peak doping concentration of $10^{19} \mathrm{~cm}^{-3}$ and a variable depth. Realistic electron SRH lifetimes of 500 $\mu \mathrm{s}$ in the p-type base have been chosen in all the cases [11]. Fig. 4 shows how the top $\mathrm{GaAs}_{0.7} \mathrm{P}_{0.3}$ layers (top cell + buffer) absorb all the radiation for the wavelengths up to $690 \mathrm{~nm}$, according to its $1.78-\mathrm{eV}$ direct gap. Regarding the performance of the LT-BSF, it is clearly seen how the improvement in the cell photoresponse is not very significant when working with shallow BSF layers $(<500 \mathrm{~nm})$. In these cases, the built-in electric field created by moderately doped shallow profiles is not strong enough to counterbalance the high recombination of the rear full-area contact.

To have a more complete picture of the LT-BSF impact on the overall $\mathrm{Si}$ bottom cell performance, the variation in $J_{\mathrm{SC}}$ (without ARC) and $V_{\mathrm{OC}}$ at 1 -sun AM1.5G has been studied in a wider range of peak doping concentrations and depths. These results, summarized in Fig. 5, show that for peak dopings lower than $10^{19} \mathrm{~cm}^{-3}$, obtaining a $J_{\mathrm{SC}}$ higher than $14 \mathrm{~mA} / \mathrm{cm}^{2}$ is only feasible for BSF depths larger than $1 \mu \mathrm{m}$. Shallower BSFs will only work relatively well if a peak concentration well within the $10^{19} \mathrm{~cm}^{-3}$ range could be eventually reached. As it is well established, the rear passivation has an even greater impact on $V_{\mathrm{OC}}$. Without any rear passivation, the high saturation current density caused by the full-area rear contact decreases $V_{O C}$ down to $524 \mathrm{mV}$; the value is in good 

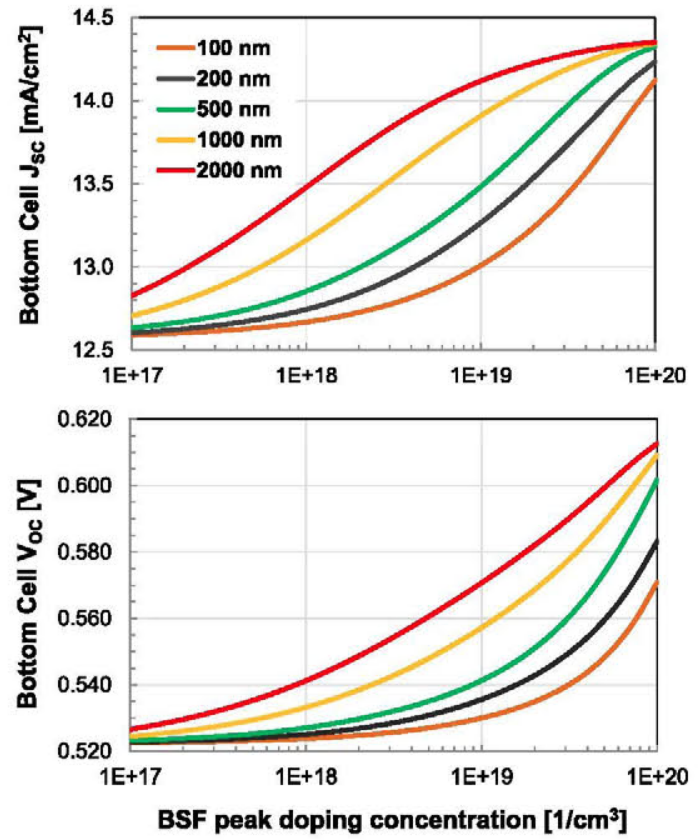

Fig. 5. $\quad J_{\mathrm{SC}}$ (top) and $V_{\mathrm{OC}}$ (bottom) at 1-sun AM1.5G for the bottom $\mathrm{Si}$ cell with ERFC-type LT-BSF as a function of the LT-BSF peak doping concentration and depth.

agreement with the first published experimental data [12]. The LT-BSF approach provides little improvement on this baseline result. Getting some extra $50 \mathrm{mV}$ is only feasible for $N_{\text {peak }} \geq 5 \times 10^{19} \mathrm{~cm}^{-3}$ and thickness $\geq 200 \mathrm{~nm}$. $V_{\mathrm{OC}}$ exceeding $600 \mathrm{mV}$ would only be possible for $N_{\text {peak }}$ as high as $10^{20} \mathrm{~cm}^{-3}$ and thickness $>500 \mathrm{~nm}$, values that could be hard to get considering the low thermal load restriction of this approach.

\section{B. PERC- and PERL-Like Rear Passivation}

A second alternative for rear passivation would be to reproduce the also well-known PERC developed by Blakers et al. [13] in 1989. In this case, rear-surface passivation is obtained by depositing dielectric layers and using point metal contacts. In fact, this approach was developed to avoid the standard high-temperature surface passivation schemes in $\mathrm{Si}$ (as thermal oxidation). Typical candidates for $\mathrm{p}-\mathrm{Si}$ are $\mathrm{SiN}_{x}$ [14], $\mathrm{Al}_{2} \mathrm{O}_{3}$ [15], or stacks of these layers and $\mathrm{SiO}_{x}$ [16] deposited by deposited by plasmaenhanced chemical vapor deposition (PECVD) or atomic layer deposition (ALD), at temperatures below $350{ }^{\circ} \mathrm{C}$. Despite of being greatly dependent on the quality and composition of the dielectric layer and/or the presence of fixed charge, rear effective surface recombination velocities (SRVs) around or lower than $100 \mathrm{~cm} / \mathrm{s}$ are regularly obtained with this approach [17]. In addition, backside processing would be completed using $\mathrm{Al}$ evaporation-or sputtering-followed by a laser process to form locally fired point contacts [Fig. 1(b)] [18]. The laser-fired contact (LFC) technique allows forming ohmic contacts between the $\mathrm{Al}$ layer and $\mathrm{Si}$ without the need for a photolithographic step. As the laser power, pulse duration and interval between pulses can be adjusted;

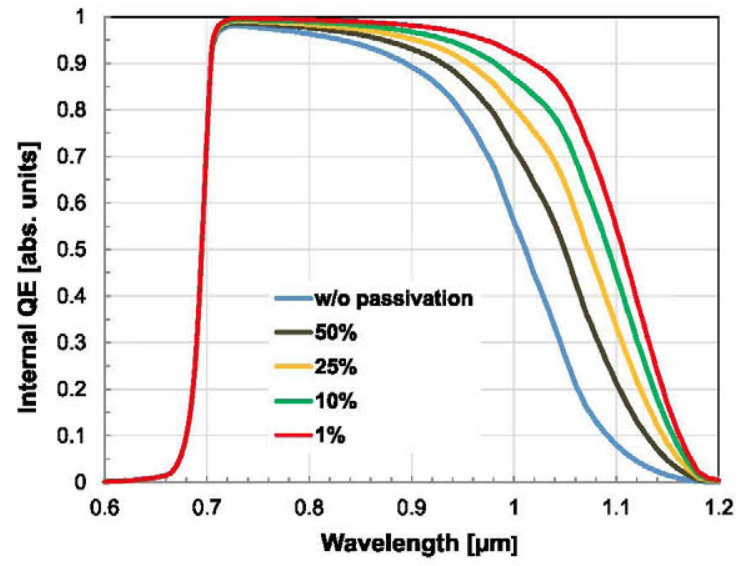

Fig. 6. IQE for the bottom Si cell including a $300-\mathrm{nm} \mathrm{SiN}_{x}+1-\mu \mathrm{m}$ Al rear layers, as a function of the rear contact coverage area (in percentage) for a $1 \times 1 \mathrm{~mm}^{2} \mathrm{GaAsP} / \mathrm{Si}$ simulation domain.

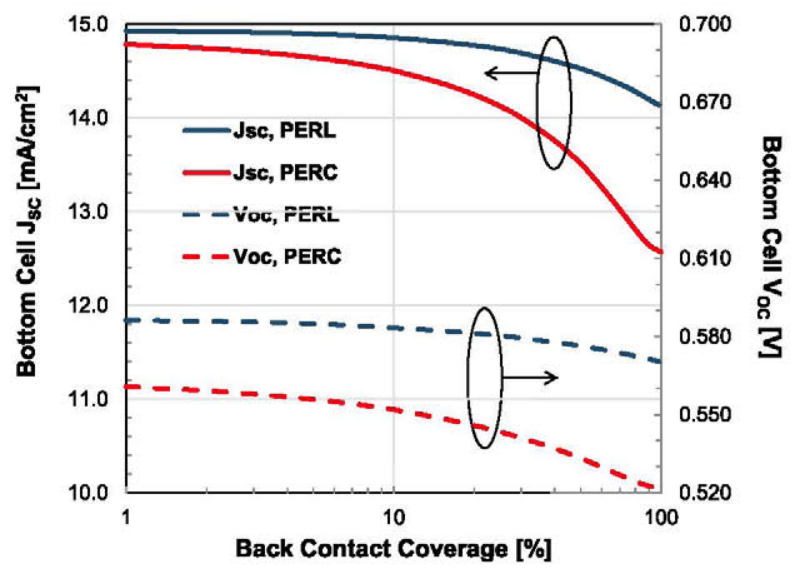

Fig. 7. $J_{\mathrm{SC}}$ and $V_{\mathrm{OC}}$ at 1-sun AM1.5G for the bottom Si cell including a $300-\mathrm{nm} \mathrm{SiN} \mathrm{Si}_{x}+1-\mu \mathrm{m} \mathrm{Al}$ rear layers as a function of the rear contact coverage area (in percentage) for a $1 \times 1 \mathrm{~mm}^{2}$ GaAsP/Si simulation domain. Red lines: PERC approach. Blue lines: local BSF under the contacts (PERL).

it is expected that the thermal budget for the top III-V layers could be kept within reasonable limits.

Fig. 6 shows the simulated IQE for the Si bottom cell of a device as the one depicted in Fig. 1(b) that includes a 300-nm $\mathrm{SiN}_{x}+1-\mu \mathrm{m} \mathrm{Al}$ rear layers, as a function of the rear contact coverage area (in percentage) for an SRH electron lifetime of $500 \mu \mathrm{s}$. The rear passivation under the dielectric is modeled by setting an effective back SRV of $100 \mathrm{~cm} / \mathrm{s}$ (no dielectric fixed charge at the interface is used). Fig. 6 clearly shows that the lower the rear metal-contacted area, the greater the photoresponse in the infrared region. This result is not only due to the reduced recombination in the contact area but also due to the greater quality of the rear $\mathrm{Al}$ mirror, which has been greatly improved by the insertion of the dielectric layer. In the end, this mirror reflects the nonabsorbed part of the incoming spectrum, enhancing the infrared response of the solar cell. With this approach, values for $J_{\mathrm{SC}}$ (without ARC) at 1-sun AM1.5G as high as $14.8 \mathrm{~mA} / \mathrm{cm}^{2}$ are expected for a rear contact coverage area of $1 \%$ (see the red solid line in Fig. 7).

Interestingly, LFC processes under certain firing conditions allow to create $\mathrm{p}^{++}$-doped regions under the contacts, which 

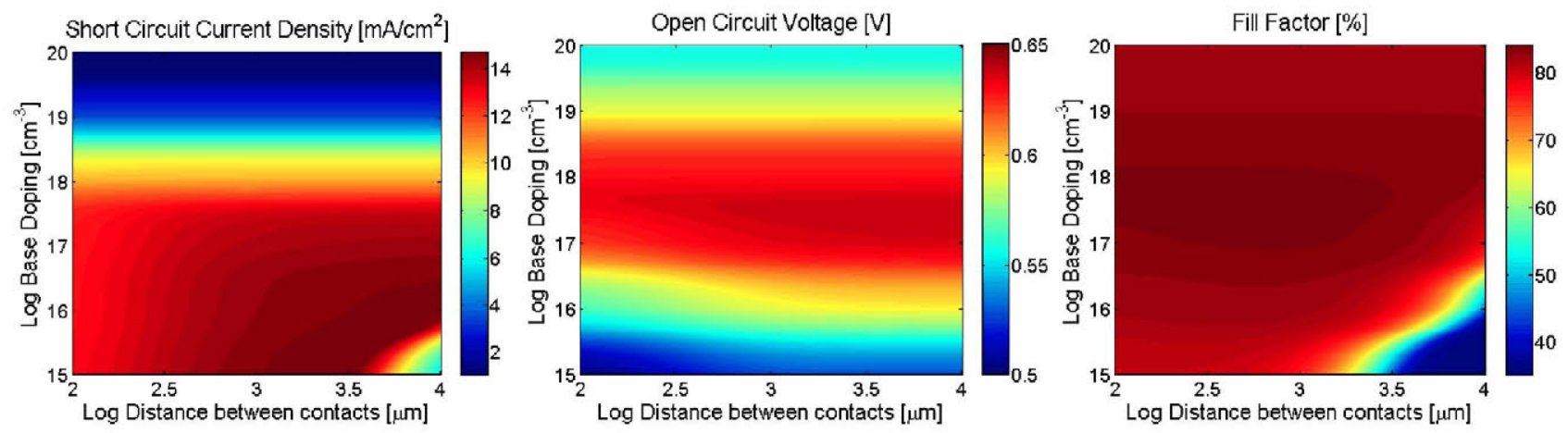

Fig. 8. Si bottom cell performance under 1-sun AM1.5G for a PERC-like structure with a typical laser-fired rear point contact of $100 \mu \mathrm{m}$ in diameter, as a function of base doping and distance between the contacts (without ARC). Left: $J_{\mathrm{SC}}$. Center: $V_{\mathrm{OC}}$. Right: FF.

are beneficial not only to the achievement of low specific contact resistances in low-resistivity Si substrates but also to the formation of local BSFs that minimize recombination. This rear-surface passivation approach matches the wellknown PERL cell structure, developed by Wang et al. [19] in 1990, with which $25.0 \%$ efficient $\mathrm{Si}$ cells were manufactured in 1999 [20]. Consequently, if a 2- $\mu$ m-thick ERFC-type local BSF with a peak doping of $10^{19} \mathrm{~cm}^{-3}$ is assumed under the contacts, $J_{\mathrm{SC}}$ becomes almost independent of the contact coverage in the $1 \%-10 \%$ range, keeping the $J_{\mathrm{SC}}$ value as high as $14.9 \mathrm{~mA} / \mathrm{cm}^{2}$ (Fig. 7). The impact of adding the local BSF under the contacts is most marked in $V_{\mathrm{OC}}$, obtaining at least $30 \mathrm{mV}$ more than PERC-like Si cells while the contacted rear area lies within the $1 \%-10 \%$ range. The decrease in both $J_{\mathrm{SC}}$ and $V_{\mathrm{OC}}$ observed for the coverages from $10 \%$ to $100 \%$ is due to the progressive substitution of the dielectric-enhanced reflector by the fired $\mathrm{Al}$ layer, whose reflectivity and surface passivation properties are poorer.

In practice, the laser used to fire the rear contacts usually has a certain beam diameter, which results in a circular contact with a fixed area [18]. The rear point-contacted cell structure is then optimized by modifying the distance between the fired contacts. In this sense, we have studied the influence of the distance between the contacts together with the base doping on the Si bottom cell performance for a PERC-like structure. Fig. 8 (left) shows how the highest $J_{\mathrm{SC}}$ is obtained for a base doping of $10^{16} \mathrm{~cm}^{-3}$ and the distance between the contacts as high as $10^{4} \mu \mathrm{m}$. However, FF is greatly decreased by the combination of a low-doped base and a distance between the contacts greater than 1-2 mm [Fig. 8 (right)], due to an increased series resistance in the base of the Si subcell. The highest $V_{\mathrm{OC}}$ [Fig. 8 (center)] of $\sim 630 \mathrm{mV}$ is reached for a doping concentration in the low $10^{17} \mathrm{~cm}^{-3}$ range (a fixed SRH lifetime of $100 \mu \mathrm{s}$ is assumed for all doping concentrations). In summary, the $\mathrm{Si}$ bottom cell would maximize its performance for a substrate doping of $1-2 \times 10^{17} \mathrm{~cm}^{-3}$ and a distance between the contacts in the $2-4-\mathrm{mm}$ range.

\section{HIT-Like Rear Passivation}

The third and last approach considered in this paper to passivate the rear surface of the $\mathrm{Si}$ bottom subcell at low temperature is based on using hydrogenated amorphous $\mathrm{Si}$.

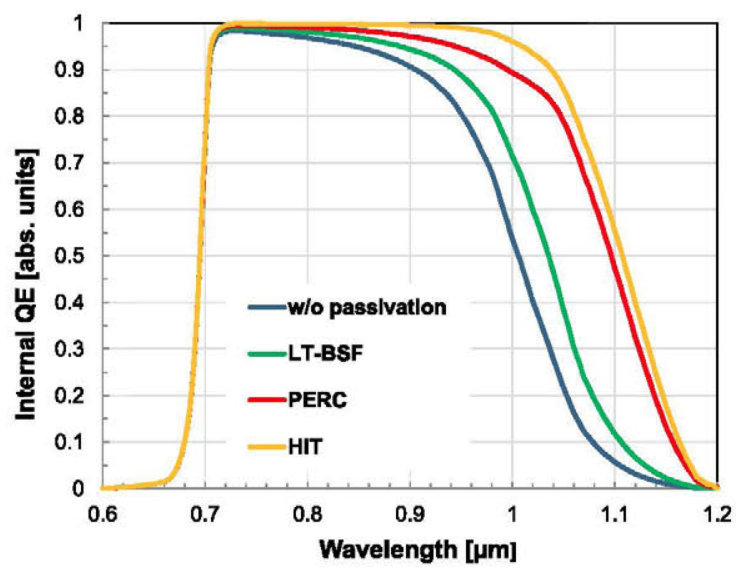

Fig. 9. IQE comparison for the Si bottom cell in a GaAsP/Si structure, under 1-sun AM1.5G illumination for standard (without passivation), LT-BSF $\left(10^{19} \mathrm{~cm}^{-3}\right.$ and $\left.0.5 \mu \mathrm{m}\right)$, PERC-like ( $1 \%$ contact coverage and effective rear SRV of $100 \mathrm{~cm} / \mathrm{s})$, and HIT $(10 \mathrm{~nm}$ and effective rear SRV of $10 \mathrm{~cm} / \mathrm{s})$.

It consists of a thin $(\sim 10 \mathrm{~nm})$ intrinsic a-Si:H layer deposited on the p-type c-Si followed by a p-type a-Si:H layer. This passivation scheme was used in the HIT Si solar cell developed by SANYO in 1990 [21]. Record efficiencies as high as $24.7 \%$ [22] and $25.6 \%$ (with interdigitated back contacts) by SANYO (now Panasonic) [23] have been confirmed in 2014 for HIT Si solar cells.

The use of a high-quality intrinsic a-Si:H layer is the key to achieving a very good rear-surface passivation, due to the effective reduction of the surface dangling bonds by hydrogenation, together with the BSF created by the $\mathrm{c}-\mathrm{Si} / \mathrm{a}-\mathrm{Si}$ heterojunction. Rear effective SRV lower than $10 \mathrm{~cm} / \mathrm{s}$ is easily reached with this approach, allowing $V_{O C}$ as high as $750 \mathrm{mV}$ in HIT solar cells at 1-sun illumination [22]. More interestingly, high-quality a-Si:H layers can be deposited by PECVD at very low temperatures $\left(\sim 200^{\circ} \mathrm{C}\right)$, which makes this alternative an excellent candidate to keep the thermal budget of the III-V/Si structure to a minimum. The rear stack would be completed by evaporating a metal (i.e., $\mathrm{Al}$ ) layer to enhance back reflection [Fig. 1(c)]. When passivating only the rear contact, a transparent ITO layer between the a-Si:H layers and the rear contact metal is not compulsory [24], though its presence improves the electrical contact and increases the internal reflectance at the rear surface [25]. 
TABLE I

Typical Calculated Values for the PERformance of a Si BOTTOM CELl IN A GaAsP/Si STRUCTURE, UNDER 1-SUN AM1.5G FOR STANDARD (WITHOUT PASSIVATION), LT-BSF, PERC-LIKE, PERL-LIKE, AND HIT-LIKE

\begin{tabular}{ccccc}
\hline \hline \multirow{2}{*}{ Alternative } & \multicolumn{4}{c}{ Performance at 1-sun AM 1.5G } \\
& $\mathrm{J}_{\mathrm{SC}}\left(\mathrm{mA} / \mathrm{cm}^{2}\right)$ & $\mathrm{V}_{\mathrm{OC}}(\mathrm{mV})$ & FF (\%) & Eff. (\%) \\
\hline Standard & 12.6 & 524 & 80.8 & 5.33 \\
LT-BSF & 13.5 & 543 & 81.3 & 5.96 \\
PERC-like & 14.8 & 561 & 79.0 & 6.56 \\
PERL-like & 14.9 & 586 & 79.2 & 6.92 \\
HIT-like & 15.0 & 628 & 79.6 & 7.50 \\
\hline \hline
\end{tabular}

Fig. 9 shows IQE, simulated for a HIT-like passivated $\mathrm{Si}$ bottom subcell with $10-\mathrm{nm}$ a-Si intrinsic/p-type layers, an $\mathrm{Al} 1-\mu \mathrm{m}$-thick back reflector, and assuming an effective back SRV of $10 \mathrm{~cm} / \mathrm{s}$ at the $\mathrm{c}-\mathrm{Si} / \mathrm{a}-\mathrm{Si}$ interface. The a-Si input parameters for the simulations are taken from [26]. IQE for the standard (without rear passivation), LT-BSF, and PERC-like alternatives are also included for comparison. More details are given in the caption of Fig. 9. Both the LT-PERC and HIT-like schemes are much more efficient in terms of enhancing collection and photon reflection for longer wavelengths, as compared with the low-doped shallow BSF present at the LT-BSF. However, the HIT-like scheme shows a higher IQE in the 900-1050-nm wavelength range as a result of its better rear-passivation properties.

To conclude the comparison between the reviewed alternatives, Table I shows the simulated Si bottom cell performance under 1-sun AM1.5G for each configuration. Compared with the nonpassivated cell, the LT-BSF, PERC-like, PERL-like, and HIT-like schemes lead to an increment in $J_{\mathrm{SC}}$ of $0.9,2.2$, 2.3 , and $2.4 \mathrm{~mA} / \mathrm{cm}^{2}$, respectively (without ARC). Regarding $V_{\mathrm{OC}}$, the calculated increments are 19,37,62, and $104 \mathrm{mV}$. Though the FF for the HIT-like is slightly lower (due to the higher series resistance of the intrinsic a-Si:H layer), it is by far the approach with which a larger improvement is expected, as a result of its excellent passivating properties, together with being the option that keeps the thermal budget of the III-V/Si structure to a minimum. Though the practical implementation of complete GaAsP/Si DJSC is still in an early stage [2], [3], future experimental efforts should be focused on validating these conclusions.

\section{CONCLUSiON}

There are remarkable differences between a conventional standalone Si solar cell and the Si subcell integrated into a III-V/Si solar cell stack. In the latter one, only the higher wavelengths reach the Si subcell, so they are in average absorbed farther from the front $\mathrm{Si}$ subcell surface, this front surface is passivated by the nucleation layer heterostructure, and there is no lateral conduction in the Si subcell emitter, which is typically manufactured by epitaxy and uniformly doped. In addition, once the III-V stack has been grown over the Si substrate, there is a huge limitation in the thermal load that the structure can handle without degrading the quality of the III-V upper layers. Then, to achieve highly efficient III-V/Si solar cells, the configuration of the Si bottom subcell has to be compatible with maximizing the device performance and maintaining the physical integrity of the tandem structure.

In that quest, this paper has reviewed using numerical simulations the adequacy of three well-known rear-surface passivation schemes to maximize the $\mathrm{Si}$ bottom cell performance in a GaAsP/Si DJSC while keeping the thermal budget as low as possible. First, an LT-BSF strategy is discussed. It is seen that the improvement in the cell performance is moderate, being basically driven by the peak doping concentration and depth attainable with an LT-BSF approach. A PERC- or PERL-like rear-surface approach combined with LFCs is much more effective. Finally, it is discussed how the most promising approach, combining the lowest processing temperatures and the highest $\mathrm{Si}$ bottom cell performance improvements, is based in using a HIT-like (rear intrinsic/ p-doped a-Si:H) passivation strategy.

\section{REFERENCES}

[1] J. F. Geisz, J. M. Olson, M. J. Romero, C.-S. Jiang, and A. G. Norman, "Lattice-mismatched GaAsP solar cells grown on silicon by OMVPE," in Proc. 4th IEEE World Conf. Photovolt. Energy Convers., Waikoloa, HI, USA, May 2006, pp. 772-775.

[2] T. J. Grassman et al., "Characterization of metamorphic GaAsP/Si materials and devices for photovoltaic applications," IEEE Trans. Electron Devices, vol. 57, no. 12, pp. 3361-3369, Dec. 2010.

[3] K. N. Yaung, J. R. Lang, and M. L. Lee, "Towards high efficiency GaAsP solar cells on (001) GaP/Si," in Proc. 40th IEEE PVSC, Denver, CO, USA, Jun. 2014, pp. 831-835.

[4] T. Roesener et al., "MOVPE growth of III-V solar cells on silicon in $300 \mathrm{~mm}$ closed coupled showerhead reactor," in Proc. 25th Eur. Photovolt. Solar Energy Conf. Exhibit., Valencia, Spain, 2010, pp. 964-968.

[5] Z. Ren et al., "Numerical analysis of radiative recombination and reabsorption in GaAs/Si tandem," IEEE J. Photovolt, vol. 5, no. 4, pp. 1079-1086, Jul. 2015.

[6] D. Martín, E. Garcia-Tabares, and I. Rey-Stolle, "Numerical simulation and experimental facts about bottom-cell optimization for III-V on silicon multijunction solar cells," in Proc. 39th IEEE PVSC, Tampa, FL, USA, Jun. 2013, pp. 873-878.

[7] J. G. Fossum, "Physical operation of back-surface-field silicon solar cells," IEEE Trans. Electron Devices, vol. 24, no. 4, pp. 322-325, Apr. 1977.

[8] Silvaco TCAD. [Online]. Available: http://www.silvaco.com/products/ tcad/, accessed Jul. 24, 2015.

[9] (2014). International Technology Roadmap for Photovoltaic (ITRPV). [Online]. Available: http://www.itrpv.net/

[10] P. Lolgen et al., "Aluminium back-surface field doping profiles with surface recombination velocities below $200 \mathrm{~cm} / \mathrm{s}$," in Proc. 23 rd IEEE PVSC, Louisville, KY, USA, May 1993, pp. 236-242.

[11] E. García-Tabarés, D. Martín, I. García, and I. Rey-Stolle, "Understanding phosphorous diffusion into silicon in a MOVPE environment for III-V on silicon for photovoltaic applications," Solar Energy Mater. Solar Cells, vol. 116, pp. 61-67, Sep. 2013.

[12] T. J. Grassman, J. A. Carlin, C. Ratcliff, D. J. Chmielewski, and S. A. Ringel, "Epitaxially-grown metamorphic GaAsP/Si dual-junction solar cells," in Proc. 39th IEEE PVSC, Tampa, FL, USA, Jun. 2013, pp. $149-153$.

[13] A. W. Blakers, A. Wang, A. M. Milne, J. Zhao, and M. A. Green, " $22.8 \%$ efficient silicon solar cell," Appl. Phys. Lett., vol. 55, no. 13, p. 1363, 1989.

[14] J. Schmidt, M. Kerr, and A. Cuevas, "Surface passivation of silicon solar cells using plasma-enhanced chemical-vapour-deposited $\mathrm{SiN}$ films and thin thermal $\mathrm{SiO}_{2}$ /plasma SiN stacks," Semicond. Sci. Technol, vol. 16, no. 3, p. $164,2001$.

[15] J. Schmidt, A. Merkle, R. Brende1, B. Hoex, M. C. M. van de Sanden, and W. M. M. Kessels, "Surface passivation of high-efficiency silicon solar cells by atomic-layer-deposited $\mathrm{Al}_{2} \mathrm{O}_{3}$," Prog. Photovolt, Res. Appl., vol. 16, no. 6, pp. 461-466, Sep. 2008.

[16] M. Hofmann et al., "Recent developments in rear-surface passivation at Fraunhofer ISE," Solar Energy Mater. Solar Cells, vol. 93, nos. 6-7, pp. 1074-1078, Jun. 2009. 
[17] S. W. Glunz, "High-efficiency crystalline silicon solar cells," Adv. OptoElectron., vol. 2007, pp. 1-15, Jul. 2007, Art. ID 97370.

[18] P. Ortega et al., "Laser-fired contact optimization in c-Si solar cells," Prog. Photovolt., Res. Appl., vol. 20, no. 2, pp. 173-180, Mar. 2012.

[19] A. Wang, J. Zhao, and M. Green, "24\% efficient silicon solar cells," Appl. Phys. Lett., vol. 57, no. 6, pp. 602-604, 1990.

[20] M. A. Green, K. Emery, Y. Hishikawa, W. Warta, and E. D. Dunlop, "Solar cell efficiency tables (version 45)," Prog. Photovolt., Res. Appl., vol. 23, no. 1, pp. 1-9, Jan. 2015.

[21] M. Taguchi et al., "Improvement of the conversion efficiency of polycrystalline silicon thin film solar cell," in Tech. Dig. Int. Photovolt. Sci. Eng. Conf., 1990, pp. 689-692.

[22] M. Taguchi et al., "24.7\% record efficiency HIT solar cell on thin silicon wafer," IEEE J. Photovolt., vol. 4, no. 1, pp. 96-99, Jan. 2014.

[23] K. Masuko et al., "Achievement of more than $25 \%$ conversion efficiency with crystalline silicon heterojunction solar cell," IEEE J. Photovolt., vol. 4, no. 6, pp. 1433-1435, Nov. 2014.
[24] M. R. Page et al., "Well passivated a-Si:H back contacts for doubleheterojunction silicon solar cells," in Proc. IEEE 4th WCPEC, Waikoloa, HI, USA, May 2006, pp. 1485-1488.

[25] Z. C. Holman et al., "Infrared light management in high-efficiency silicon heterojunction and rear-passivated solar cells," J. Appl. Phys., vol. 113 , no. 1, p. 013107, 2013.

[26] M. Filipič, Z. C. Holman, F. Smole, S. De Wolf, C. Ballif, and M. Topič, "Analysis of lateral transport through the inversion layer in amorphous silicon/crystalline silicon heterojunction solar cells," J. Appl. Phys., vol. 114 , no. 7 , p. 074504, 2013. 